\title{
Diazepam Concurrently Increases the Frequency and Decreases the Amplitude of Transient Dopamine Release Events in the Nucleus Accumbens ${ }^{[\mathbf{s}}$
}

\author{
Scott A. Schelp, Zachary D. Brodnik, Dylan R. Rakowski, Katherine J. Pultorak, \\ Asha T. Sambells, Rodrigo A. España, and Erik B. Oleson \\ University of Colorado Denver, Department of Psychology, Denver, Colorado (S.A.S., D.R.R., K.J.P., A.T.S., E.B.O.) and Drexel \\ University College of Medicine, Department of Neurobiology and Anatomy, Philadelphia, Pennsylvania (Z.D.R., R.A.E.)
}

Received March 29, 2017; accepted October 4, 2017

\begin{abstract}
Benzodiazepines are commonly prescribed anxiolytics that pose abuse liability in susceptible individuals. Although it is well established that all drugs of abuse increase brain dopamine levels, and benzodiazepines are allosteric modulators of the $\mathrm{GABA}_{\mathrm{A}}$ receptor, it remains unclear how they alter dopamine release. Using in vivo fast-scan cyclic voltammetry, we measured diazepam-induced changes in the frequency and amplitude of transient dopamine release events. We found that diazepam concurrently increases the frequency and decreases the amplitude of transient dopamine release events in the awake
\end{abstract}

and freely moving rat. The time course during which diazepam altered the frequency and amplitude of dopamine release events diverged, with the decreased amplitude effect being shorter lived than the increase in frequency, but both showing similar rates of onset. We conclude that diazepam increases the frequency of accumbal dopamine release events by disinhibiting dopamine neurons, but also decreases their amplitude. We speculate that the modest abuse liability of benzodiazepines is due to their ability to decrease the amplitude of dopamine release events in addition to increasing their frequency.

\section{Introduction}

Benzodiazepines (BZP) potentiate brain $\gamma$-aminobutyric acid (GABA) function by activating allosteric binding sites on the $\mathrm{GABA}_{\mathrm{A}}$ receptor (Sigel and Buhr, 1997). Potentiating $\mathrm{GABA}_{\mathrm{A}}$ function produces anxiolytic, sedative, and hypnotic effects in a receptor subtype-dependent manner (Rudolph and Möhler, 2006). Due to their anxiolytic properties, benzodiazepines are used clinically for the treatment of certain anxiety disorders (Dell'Osso and Lader, 2013). Many patients who are prescribed benzodiazepines take them responsibly and benefit from their therapeutic utility; however, administration of high doses of BZPs for extended durations can increase the odds of abuse in susceptible individuals (Griffiths and Weerts, 1997; Licata and Rowlett, 2008; Baldwin et al., 2013). Alarmingly, over 270,000 patients who visited emergency rooms in 2008 reported nonprescription use of benzodiazepines (Centers for

Funding for the project was provided by the National Institutes of Health [Grants R01DA031900 and R03DA038734], National Science Foundation [Grant IOS-1557755], a Boettcher Young Investigator Award, and a NARSAD Young Investigator Award.

The authors have no conflicts to disclose.

The work was previously presented as a poster presentation: Benzodiaz pines and their dual administration with ethanol increase accumbal transient dopamine release events (2016) RAKOWSKI D R, SCHELP SA, BRODNIK Z, ESPAÑA RA, PULTORAK KJ, OLESON EB. The 2016 Society for Neuroscience Annual Meeting, San Diego, CA.

https://doi.org/10.1124/jpet.117.241802.

S This article has supplemental material available at jpet.aspetjournals.org.
Disease Control and Prevention, 2010). Such benzodiazepinerelated incidents appear to be growing in prevalence, as the number of benzodiazepine-related emergency room visits increased by $82 \%$ over the preceding 5 years (Centers for Disease Control and Prevention, 2010). The current extent of BZP abuse remains unclear, as it can be difficult to disentangle pharmacotherapeutic use versus abuse; however, it is widely accepted that they are one of the most frequently prescribed anxiety medications in Western countries, where they are frequently misused (Umbricht and Velez, 2015). Despite the widespread use of BZPs, the way in which they influence the brain's neurochemistry to promote abuse remains poorly characterized.

All drugs of abuse are thought to increase dopamine (DA) concentration within the nucleus accumbens (NAc) (Di Chiara and Imperato, 1988), a neural structure highly implicated in reward-seeking and motivation (Da Cunha et al., 2012; Floresco, 2015). The NAc primarily receives afferent dopaminergic input from the ventral tegmental area (VTA) (Swanson, 1982; Ikemoto, 2007). In the awake and behaving animal, VTA DA neurons exhibit two distinct firing patterns: tonic and phasic (Grace and Bunney, 1984; Grace et al., 2007). When at rest, these DA neurons exhibit a regular pacemaker pattern of low-frequency activity $(1-5 \mathrm{~Hz})$. This basal firing pattern provides a low concentration dopaminergic "tone" in the NAc. In contrast, when animals are exposed to drugs of abuse, VTA DA neurons fire in high-frequency bursts at rates greater 
than $20 \mathrm{~Hz}$ (Willuhn et al., 2010; Covey et al., 2014). This phasic pattern contributes to high-concentration, transient release events in the NAc that are thought to be integral in promoting abuse liability (Willuhn et al., 2010; Covey et al., 2014). Several recent reports have demonstrated that various drugs of abuse with diverging mechanisms of action, including cocaine (Stuber et al., 2005; Aragona et al., 2008), amphetamine (Covey et al., 2016), cannabinoids (Cheer et al., 2004; Oleson and Cheer, 2012), opiates (Fox et al., 2017), and nicotine (Cheer et al., 2007), increase both the frequency and amplitude of these transient release events (Covey et al., 2014).

BZPs are theorized to increase DA concentration via disinhibition of DA neurons in the VTA. BZP-induced activation of GABA receptors on GABAergic interneurons is thought to contribute to this disinhibition (Tan et al., 2010, 2011). Previous studies utilizing electrophysiological recordings and pharmacological manipulations of $\mathrm{GABA}_{\mathrm{A}}$ receptor demonstrate that BZPs do indeed increase the firing rate of putative VTA DA neurons in a $\mathrm{GABA}_{\mathrm{A}}$ receptor-dependent manner (O'Brien and White, 1987; Tan et al., 2010). A BZP-induced disinhibition of DA neural activity would also suggest that indices of NAc DA signaling should be enhanced. However, microdialysis studies generally report that BZPs decrease accumbal DA concentration (Zetterström and Fillenz, 1990; Invernizzi et al., 1991; Finlay et al., 1992, 1995; Takada et al., 1993; Murai et al., 1994; Dazzi et al., 1995; Hegarty and Vogel, 1995; Motzo et al., 1997; Yoshida et al., 1999; Bentue-Ferrer et al., 2001; Rada and Hoebel, 2005; Gomez-A et al., 2017), but see Bentue-Ferrer et al. (2001). Furthermore, a recent fastscan cyclic voltammetry (FSCV) study reported that BZPs decrease the amplitude of electrically evoked accumbal DA concentrations (Gomez-A et al., 2017). In the current study, we predicted that a real-time analysis of BZP-induced accumbal DA release events would reveal an increase in their frequency, but also a decrease in their amplitude.

\section{Materials and Methods}

Subjects and Surgery. Catheterized male Long-Evans rats (Charles River Laboratories, Wilmington, MA) were singly housed under a 12:12 light:dark cycle with a 10 a.m. to 10 p.m. active period (dark phase). All experiments were conducted in the active phase. Rats (250-300 $\mathrm{g}$ at the time of surgery) were placed under isoflurane anesthesia (5\% induction, $2 \%$ maintained) for surgery conducted in a Kopf stereotaxic apparatus. A guide cannula that mates with an electrode containing micromanipulator was implanted to be aimed at the nucleus accumbens core $(+1.3$ anterior-posterior, +1.4 mediallateral relative to the bregma) or the nucleus accumbens shell $(+1.7$ anterior-posterior, +0.8 medial-lateral relative to the bregma) along with a contralateral $\mathrm{Ag} / \mathrm{AgCl}$ reference electrode. Rats were given 3 days postsurgery to recover before experiments were conducted. The University of Colorado Denver Institutional Animal Care and Use Committee approved all experiments and procedures in advance.

FSCV. Voltammetric recordings were conducted by lowering a glass-encased carbon-fiber microelectrode with a micromanipulator into the NAc and locking it into place. An initial wave form $(-0.4$ to 1.3 $\mathrm{V}$, TarHeel CV filtered with cutoff frequency of $2 \mathrm{kHz}$ for a scan rate of $400 \mathrm{~V} / \mathrm{s}$ ) was applied which allowed for the detection of DA via fastscan cycle voltammograms taken every $100 \mathrm{~ms}$. To increase electrode sensitivity, the wave form was first applied at $60 \mathrm{~Hz}$ for 30 minutes, but was reduced to $30 \mathrm{~Hz}$ before experimentation (Heien et al., 2003). To extract the DA component, principle component regression was applied to the raw voltammetric data as previously described (Heien et al., 2004). Specifically, DA and $\mathrm{pH}$ were resolved from the FSCV recordings using recording-specific training sets $(n=6 /$ analyte) to produce $\mathrm{pH}$ background-subtracted (10 consecutive scans) DA concentration files for transient analysis. Prior to performing principle component regression, current-versus-time data were smoothed using the built-in TarHeel CV smoothing option (eight-point nearestneighbor smoothing kernel). To increase the validity of calibration factors for DA assessment, we applied a recently developed computational model (Roberts et al., 2013) designed to calculate calibration factors for individual electrodes by applying known constants to background current values from each in vivo recording. By replicating Roberts et al. (2013), using 10 electrodes, we obtained a set of empirical values using multiple linear regression analysis. Our laboratory-specific coefficients are $\alpha=4.71 \mathrm{e}^{-5}, \beta=17.185, \gamma=$ 8.324 , and $\delta=-0.656$. Using these coefficients, we can calculate calibration factors for individual electrodes used in vivo by simply entering the observed total background current and the switching potential corresponding to each individual file. We also found that total background current decreased over the course of the recording sessions; thus, each 1-minute dopamine concentration trace was further normalized to its total background current (Supplemental Fig. S1).

At the end of the experiment, animals were killed with $\mathrm{CO}_{2}$, and electrolytic lesions were performed to confirm electrode placement. Brains were extracted and frozen in $-25^{\circ} \mathrm{C}$ 2-methylbutane, then stored at $-80^{\circ} \mathrm{C}$ until sectioned coronally at $50 \mu \mathrm{m}$ on a cryostat. Slices were dehydrated with baths of increasing ethanol concentration, stained with cresyl violet, preserved with histoclear (National Diagnostics, Atlanta, GA), and mounted for observation of lesion placement. Lesion placements are mapped and representative histology shown in Fig. 7.

Pharmacology. Benzodiazepines were prepared in $1 \%$ Tween 20 and sonicated for 5 minutes to dissolve the BZPs into the solution. BZPs were administered intravenously in all in vivo experiments using a cumulative dosing approach (baseline, vehicle, 0.3, 0.56, and $1.0 \mathrm{mg} / \mathrm{kg}$ ). The cumulative doses assume a half-life of $>3$ hours in the rat brain (Braestrup and Squires, 1977). Diazepam was purchased from Sigma-Aldrich (St. Louis, MO), and flumazenil was purchased from Tocris at leas (Bristol, UK).

Frequency Analysis. For every 60 seconds of recording, a polynomic line was fitted to the DA concentration data using a custom MATLAB program (MathWorks, Natick, MA) that applies the following equation to each set of DA concentration data:

$$
p(x)=p_{1} x^{2}+p_{2} x^{2}+p_{3} .
$$

The coefficients $\left(p_{1}, p_{2}, p_{3}\right)$ with the largest $R^{2}$ value were assigned for each 60 seconds of recording taken. To prevent the polynomic line from tracing up any transients (and artificially lowering the amplitude of any transients), only the values below the first fitted line were used to fit a second line with the following equation:

$$
p(x)=p_{1} x^{n}+p_{2} x^{n-1}+\ldots+p_{n} x+p_{n}+1 .
$$

The degree of the polynomial was determined by finding the lowest AIC score with the following equation:

$$
\mathrm{AIC}=n \log (R S S / n)+2 k .
$$

The coefficients $\left(p_{1}, p_{2}, p_{3} \ldots\right)$ with the largest $R^{2}$ value were assigned for each 60 seconds of recording taken for the second line. The second fitted line was subtracted from all values present in the original recording to adjust for drifting current and establish a true zero. Only values above 1 S.D. of the entire 60 -second recording were considered nonbackground noise peaks. Peaks were programmatically determined by finding the local maximum. The peak transients were then analyzed with a set of criteria to determine a true transient. The criteria required that more than 0.5 seconds had elapsed between transients for them to be considered. If less than 0.5 seconds had elapsed, then the largest of the transients was recorded as the true 
transient. We assessed the effect of using three additional intertransient intervals $(0.1,0.3$, and 1 second) in our analysis. Importantly, similar trends were observed across all conditions (Supplemental Fig. S2); however, we came to the conclusion that the 0.1 second criterion risks type- 1 statistical error, whereas the 1 second criterion risks type2 statistical error. Analysis of variance (ANOVA) and Bonferroni posthoc tests were used to assess changes in DA concentration amplitude and frequency relative to vehicle.

Statistics. All statistics were performed using SigmaPlot11 (Systat, San Jose, CA). First, Shapiro-Wilk was used to assess for normality, and Brown-Forsythe was used to assess for equal variance. Repeated-measures ANOVA and Bonferroni post-hoc tests were used for all analyses.

\section{Results}

To assess the effects of benzodiazepines on DA release, we performed FSCV in both the NAc core and shell of awake and behaving rats. DA concentration and frequency were quantified after isolating transient release events from background current (Fig. 1; also see the Frequency Analysis section in Materials and Methods). Rats were treated with either vehicle or cumulative doses of diazepam (Figs. 2A and 3A). In our amplitude analysis, we observed a significant interaction between treatment group (vehicle vs. diazepam) and treatment condition (four consecutive injections) in both the shell [Fig. 2; $\left.F_{(4,59)}=30.799, P<0.01\right]$ and the core [Fig. $3 ; F_{(4,59)}=18.009$, $P<0.01]$ of the NAc. The effect of group depended upon the dosing condition, so that under baseline and vehicle conditions, there was no difference in amplitude between the diazepam and vehicle groups (n.s.). However, amplitude in both the shell and core was significantly lower in the diazepam group versus the vehicle group under the 0.3-, 0.56-, and 1-mg/kg cumulative dosing conditions $(P<0.05$ for all conditions; Supplemental Tables S1 and S3). Similarly, the frequency analysis also revealed significant interaction between treatment group (vehicle vs. diazepam) and
A

\section{$1.0 \mathrm{mg} / \mathrm{kg}$ Diazepam}

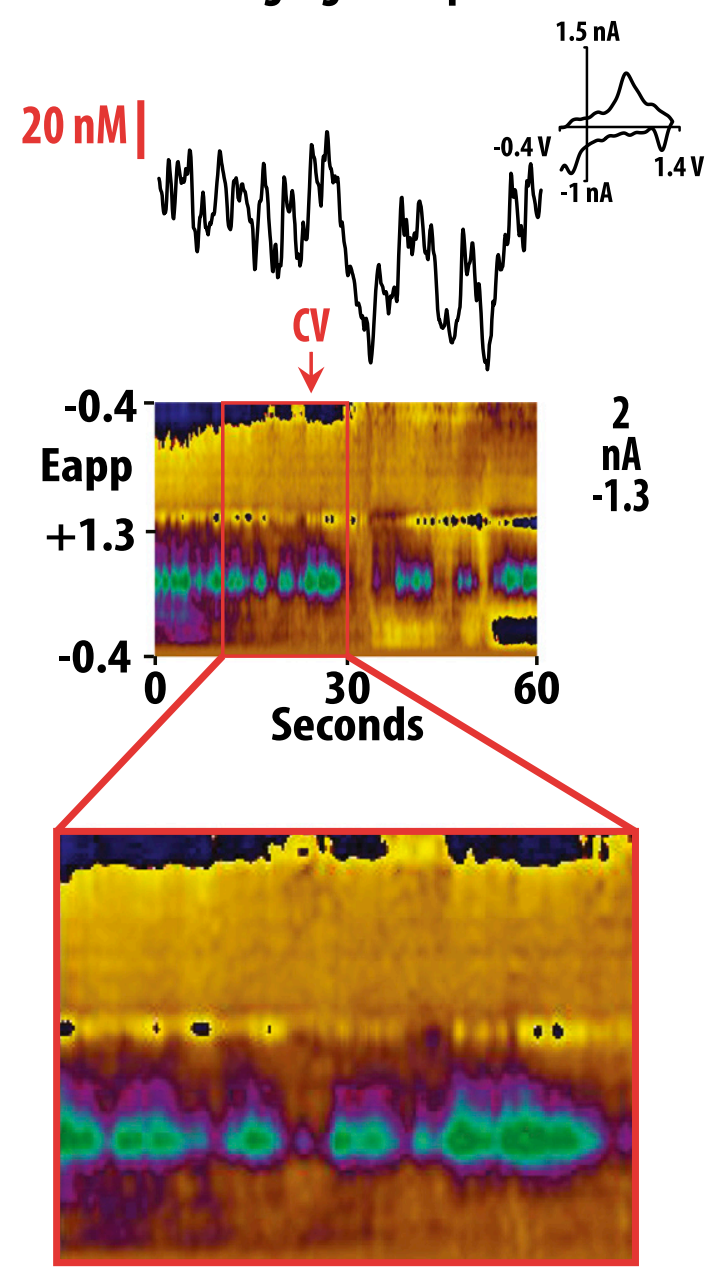

B

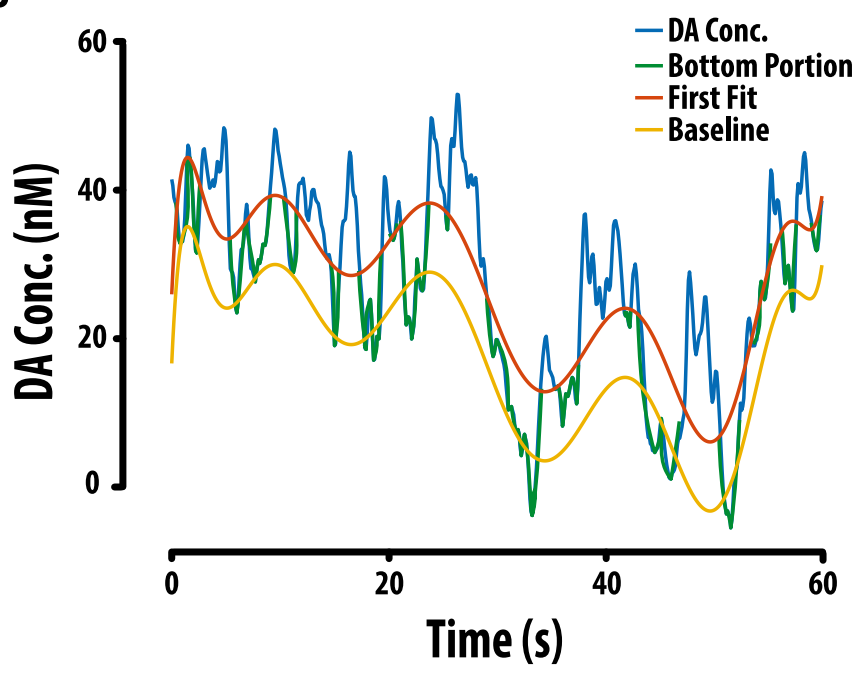

C

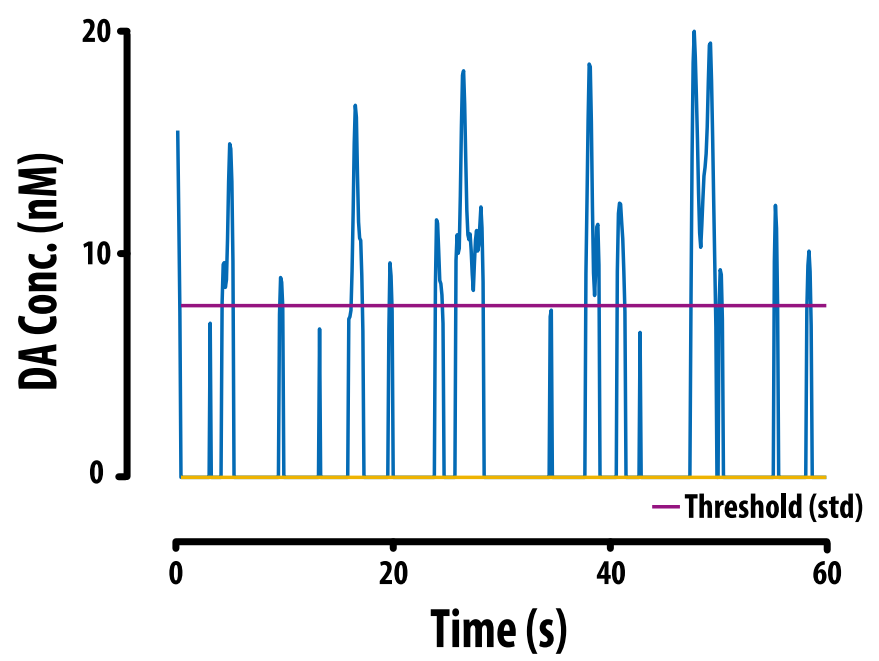

Fig. 1. DA frequency was determined by establishing threshold concentration values to isolate transient release events from background current. (A) Representative color plot and associated DA concentration (Conc.) when $1.0 \mathrm{mg} / \mathrm{kg}$ diazepam is administered i.v. Representative color plots topographically depict the voltammetric data with time on the $x$-axis, applied scan potential (Eapp) on the $y$-axis, and background-subtracted faradaic current shown on the $z$-axis in pseudocolor. DA release events can be identified by an oxidation peak (green) at $+0.6 \mathrm{~V}$. (B) Extracted DA concentration was then fitted with a polynomic line shifted by +3 times the standard deviation of a region with minimal transient activity. (C) Only release events above the threshold $(3 \times$ S.D. $)$ that were more than 0.5 seconds apart were counted as transients. Conc., concentration; CV, cyclic voltammogram. 
A

\section{Diazepam NAc Shell $(n=6)$}

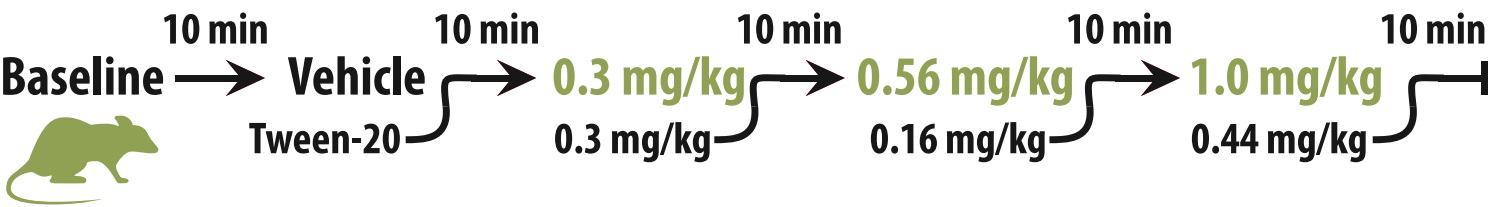

B

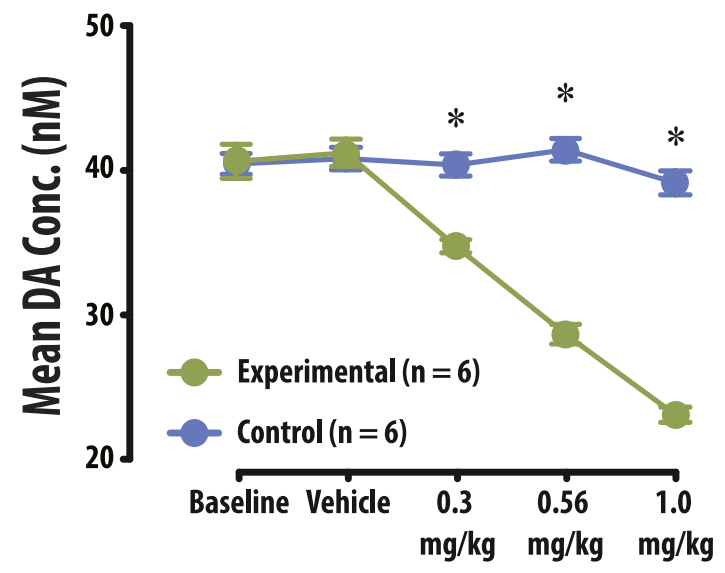

C

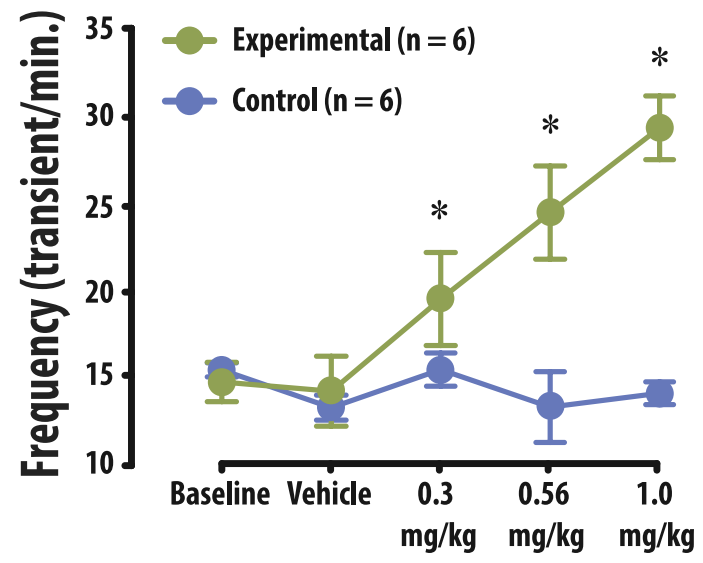

D

Baseline
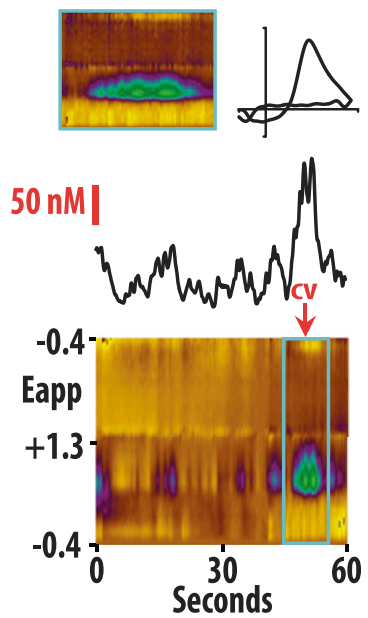

Vehicle
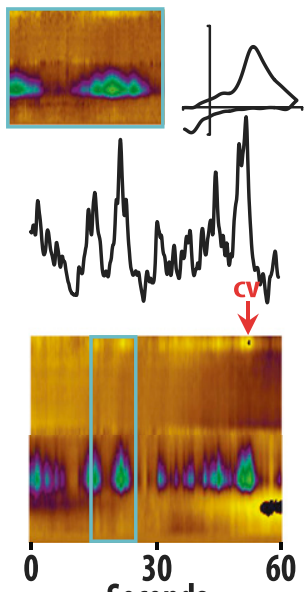

Seconds

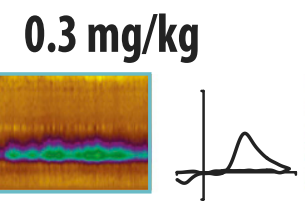

$0.56 \mathrm{mg} / \mathrm{kg}$
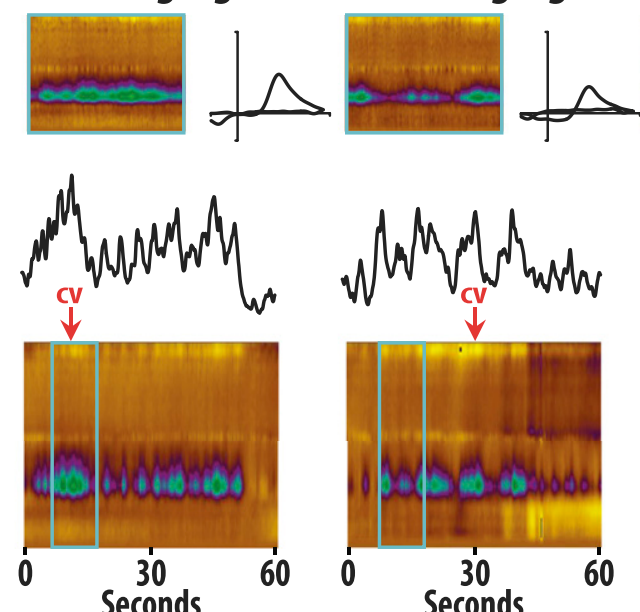

Seconds

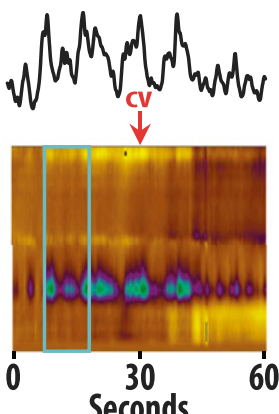

Seconds
$1.0 \mathrm{mg} / \mathrm{kg}$
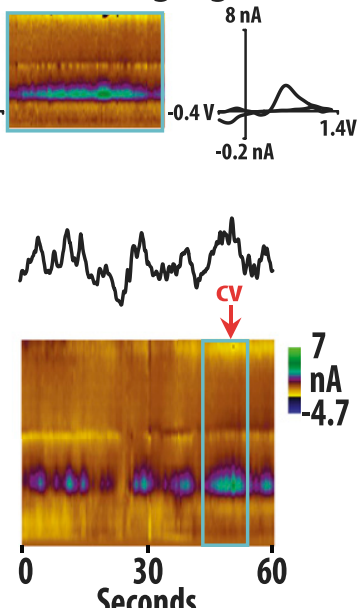

Fig. 2. Diazepam decreased amplitude of DA concentration (Conc.) and increased the frequency of transient release events in the NAc shell. (A) Tenminute baseline recording preceded the i.v. of vehicle, $0.3,0.56$, and $1.0 \mathrm{mg} / \mathrm{kg}$ diazepam (cumulative). (B) Diazepam decreased DA concentration

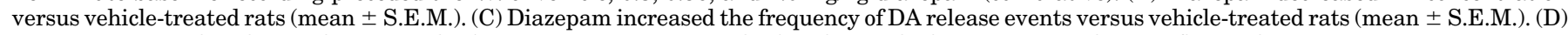
Representative color plots and associated DA concentration traces under baseline, vehicle, $0.3,0.56$, and $1.0 \mathrm{mg} / \mathrm{kg}$ conditions.

treatment condition (four consecutive injections) in both the shell [Fig. $\left.2 ; F_{(4,59)}=13.579, P<0.01\right]$ and the core [Fig. $3 ; F_{(3,63)}=$ 18.305, $P<0.01]$ of the NAc. As in the amplitude analysis, the frequency of DA release events was not different between the diazepam and vehicle groups under baseline or vehicle conditions (n.s.). However, the frequency of DA release events in both the shell and core was significantly higher in the diazepam group versus the vehicle group under the $0.3-, 0.56-$, and $1-\mathrm{mg} / \mathrm{kg}$ cumulative dosing conditions $(P<0.05$ for all conditions; Supplemental Tables S2 and S4).
The effects of diazepam on dopamine release were reversed by the selective BZP antagonist flumazenil (Fig. 4). Two groups of rats were used: an experimental group that received diazepam and then flumazenil, and a control group that received diazepam and then flumazenil. These two groups were assessed under three different conditions: baseline, diazepam or vehicle, then flumazenil (Fig. 4A). A two-way repeated-measures ANOVA revealed a significant interaction between group and treatment condition $\left[F_{(2,23)}=7.554, P<\right.$ 0.01] with the group effect being dependent upon the 
A

Diazepam NAc Core $(n=6)$
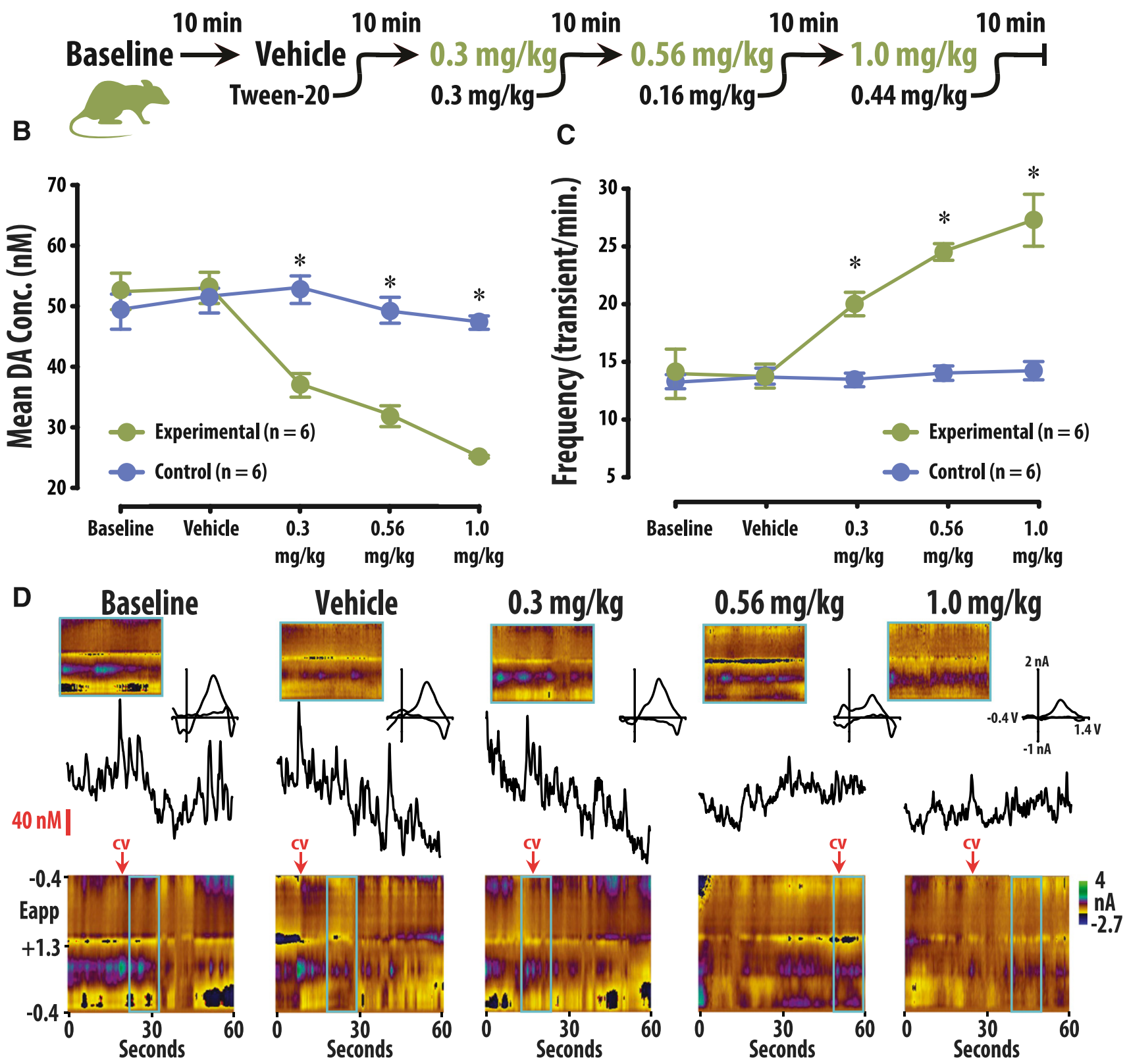

Fig. 3. Diazepam decreased DA concentration (Conc.) amplitude but increased the frequency of release events in the NAc Core. (A) Ten-minute recordings in the NAc core were conducted to establish a baseline, and then after vehicle, $0.3,0.56$, and $1.0 \mathrm{mg} / \mathrm{kg}$ cumulative doses (i.v.) of diazepam. (B) DA concentration (mean \pm S.E.M.) decreased in the NAc core after diazepam administration (vs. vehicle-treated rats). (C) The frequency of transient DA release events (mean \pm S.E.M.) increased in the NAc core after diazepam administration (vs. vehicle-treated rats). (D) Representative color plots and associated DA concentration traces for baseline, vehicle, $0.3,0.56$, and $1.0 \mathrm{mg} / \mathrm{kg}$ cumulative doses of diazepam.

treatment. No significant difference in either frequency or amplitude was observed between groups under baseline or flumazenil conditions. However, amplitude was significantly lower $(P<0.05$ vs. vehicle control group; Supplemental Table S5) and frequency was significantly higher $(P<0.05$ vs. vehicle control group; Supplemental Table S6) in the experimental group following diazepam treatment.

To further explore the mechanism of action of BZPs, we performed a time course-study to assess if the diazepaminduced changes in frequency and amplitude occur in parallel (Fig. 5). Diazepam $(1.0 \mathrm{mg} / \mathrm{kg})$ or vehicle was administered to separate groups, and changes in accumbal core DA concentration were recorded over 120 minutes. To illustrate subject-specific trends and overall variability, individual DA concentration points are depicted in Fig. 5, A and B. Vehicle failed to produce a significant change in either amplitude or frequency (Fig. 5, C and E; n.s.). Separate one-way repeated-measures ANOVA revealed diazepam significantly changed dopamine amplitude [Fig. 5D; $\left.F_{(120,483)}=1.519, P<0.01\right]$ and frequency [Fig. $5 \mathrm{E}$; $\left.F_{(120,483)}=1.306, P=0.032\right]$. We defined a return to baseline as the first point where a significant change from baseline was directly followed by an insignificant change from baseline. 
A

\section{Diazepam and Flumazenil (BZP Antagonist) NAc Core $(n=4)$}

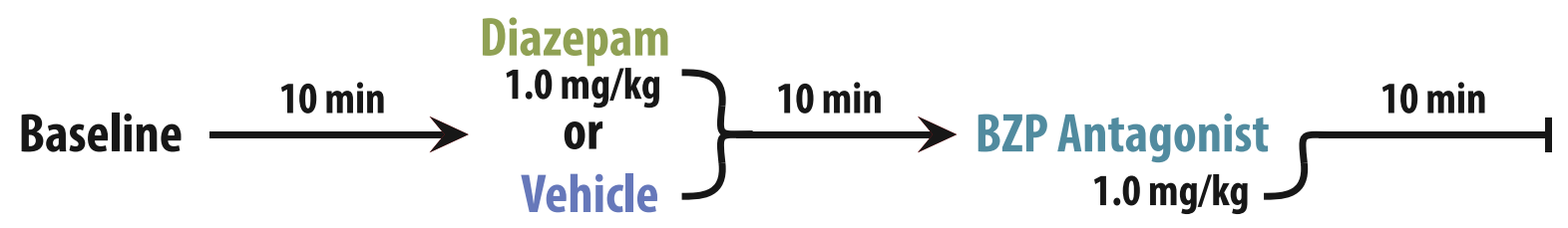

B

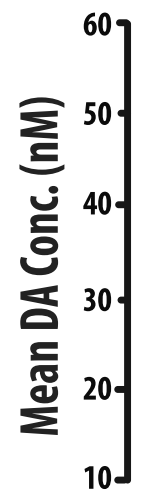

D

\section{$1.0 \mathrm{mg} / \mathrm{kg}$ Diazepam}

C

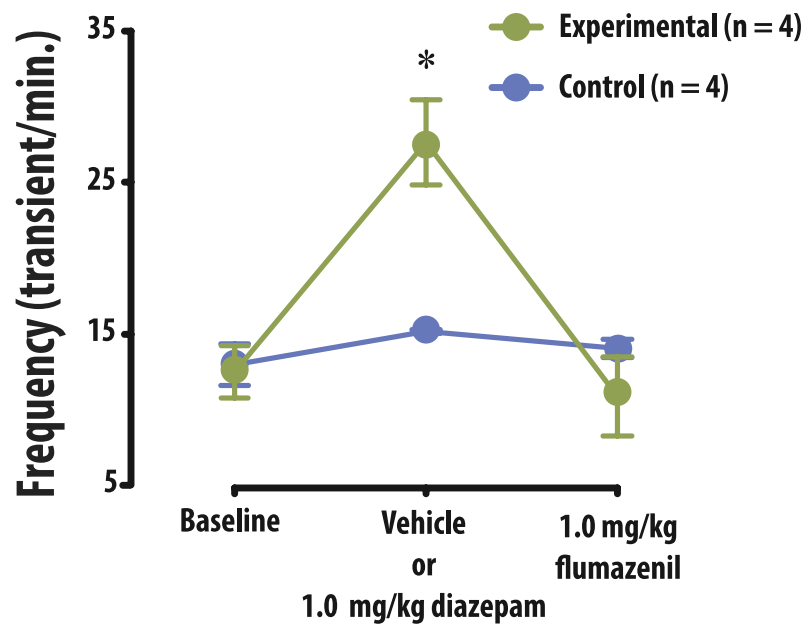

$1.0 \mathrm{mg} / \mathrm{kg}$ Diazepam + Flumazenil

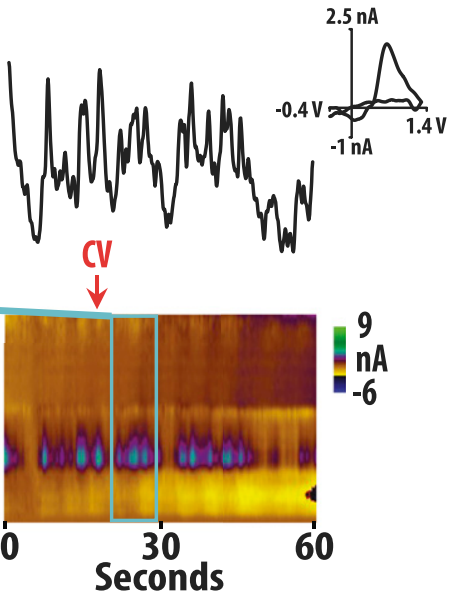

Fig. 4. The BZP receptor antagonist flumazenil reversed the decreased amplitude and increased frequency induced by the administration of diazepam. (A) Ten-minute recordings of the NAc core were conducted following administration of either $1.0 \mathrm{mg} / \mathrm{kg}$ diazepam and $1.0 \mathrm{mg} / \mathrm{kg}$ flumazenil (experimental group) or vehicle and $1.0 \mathrm{mg} / \mathrm{kg}$ flumazenil (control group). (B and C) In the experimental group (vs. control), diazepam decreased amplitude and increased frequency, effects that were reversed by flumazenil. (D) Representative color plots and associated DA concentration (Conc.) traces for $1.0 \mathrm{mg} / \mathrm{kg}$ diazepam and $1.0 \mathrm{mg} / \mathrm{kg}$ diazepam with $1.0 \mathrm{mg} / \mathrm{kg}$ flumazenil.

Bonferroni post-hoc analysis revealed that diazepam-induced decreases in the amplitude of DA transients recovered at minute 101, whereas diazepam-induced increases in the frequency of events recovered at minute $52(P<0.05$ vs. baseline). The divergent time course may suggest that distinct mechanisms alter BZP-induced changes in DA frequency and amplitude.

To further analyze the effects of diazepam on the frequency and amplitude of DA transients, we created histograms depicting total values (frequency and amplitude) across all conditions (core, shell, and all doses of diazepam; Fig. 6). The histograms illustrate that there is both a diazepam-induced loss of higher amplitude DA events and an increase in lower amplitude DA events.

\section{Discussion}

BZPs are a commonly used pharmacotherapy for anxiety disorders that can exhibit abuse liability in susceptible individuals. Although it is well established that BZPs are allosteric modulators of the $\mathrm{GABA}_{\mathrm{A}}$ receptor (Tan et al., 2010, 

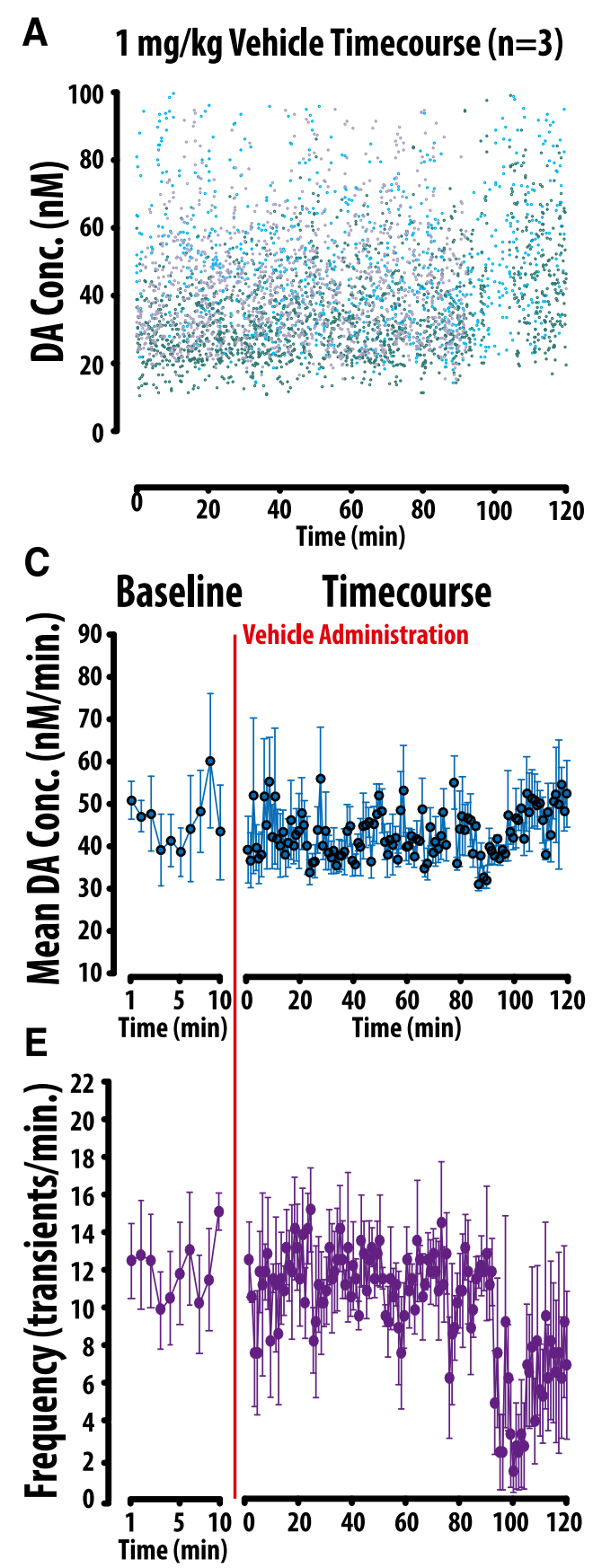
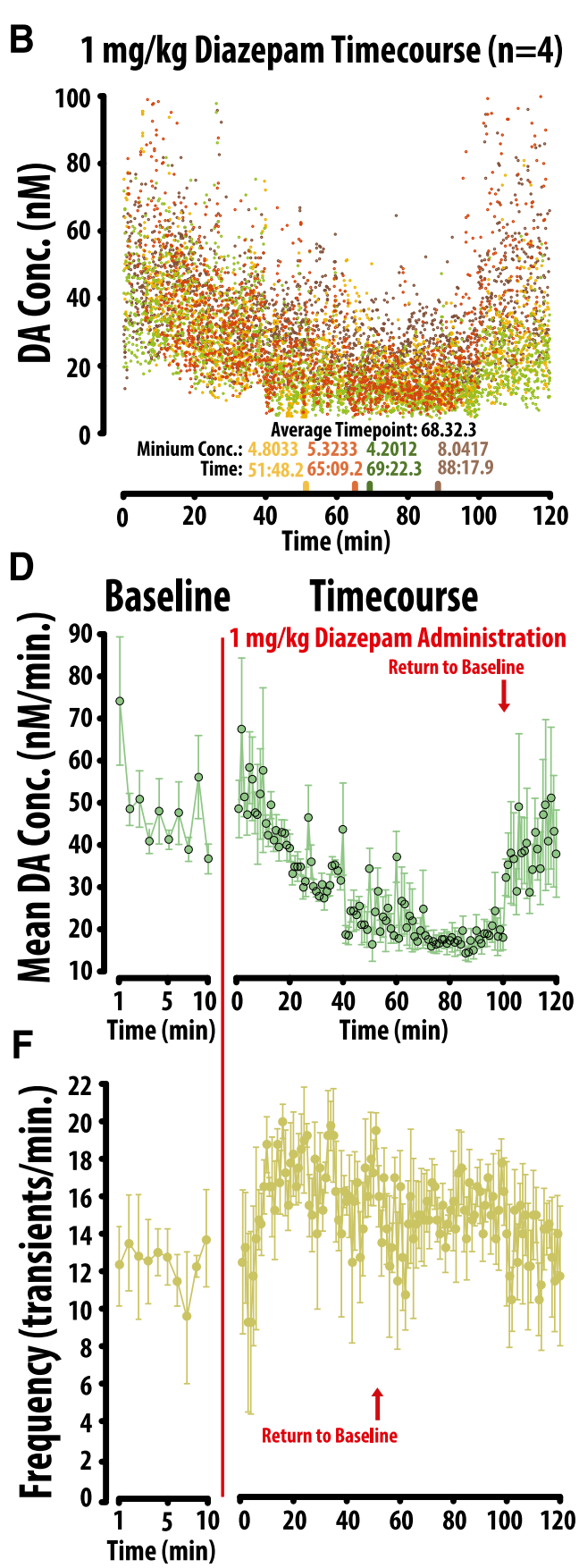
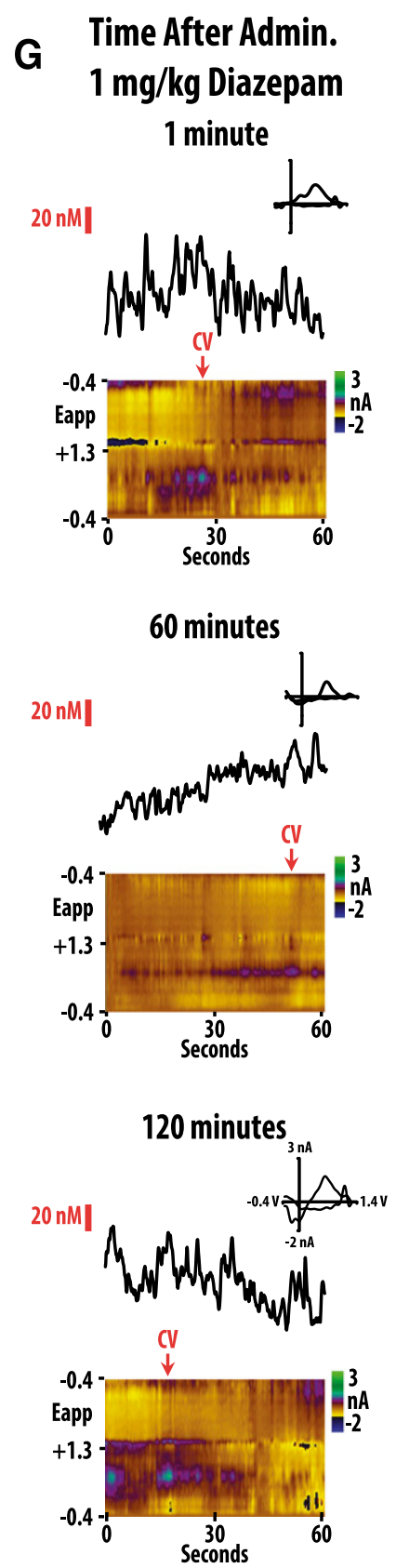

Fig. 5. The changes in frequency versus amplitude of DA induced by $1.0 \mathrm{mg} / \mathrm{kg}$ diazepam occur across divergent time-courses. All DA concentration data are plotted across the 120 minute recording session following vehicle (A) and diazepam (B) treatment. (C, D) In comparison to vehicle (left), diazepam decreases mean (+/- SEM) dopamine concentration, an effect that recovered after 100min. (E, F). In comparison to vehicle (left), diazepam increased the mean frequency (+/- SEM) of dopamine release events, an effect that recovered after 50min. (G) Representative color plots and associated DA concentration traces for $1.0 \mathrm{mg} / \mathrm{kg}$ diazepam at 1 minute, 60 minutes, and 120 minutes.

2011), it remains unclear how they alter DA release. All drugs of abuse are thought to increase brain DA levels (Di Chiara and Imperato, 1988), and the electrophysiology literature indicates that BZPs disinhibit VTA DA neurons (Tan et al., 2010, 2011); however, the microdialysis literature generally reports that BZPs decrease accumbal DA concentration (Zetterström and Fillenz, 1990; Invernizzi et al., 1991; Finlay et al., 1992, 1995; Takada et al., 1993; Murai et al., 1994; Dazzi et al., 1995; Hegarty and Vogel, 1995; Motzo et al., 1997; Yoshida et al., 1999; Bentue-Ferrer et al., 2001; Rada and Hoebel, 2005; Gomez-A et al., 2017), but see Bentue-Ferrer et al. (2001). Although microdialysis studies show a net reduction in extracellular DA concentration, the temporal resolution provided by this technique makes it difficult to discern whether a reduction in the amplitude of transient release events contributes to this effect. Additionally, a recent FSCV study demonstrated that BZPs decrease electrically evoked DA release in the NAc of anesthetized rats (Gomez-A et al., 2017). Our study builds upon these data by demonstrating the effects of diazepam on naturally occurring accumbal transient release events in the awake and freely moving animal. 

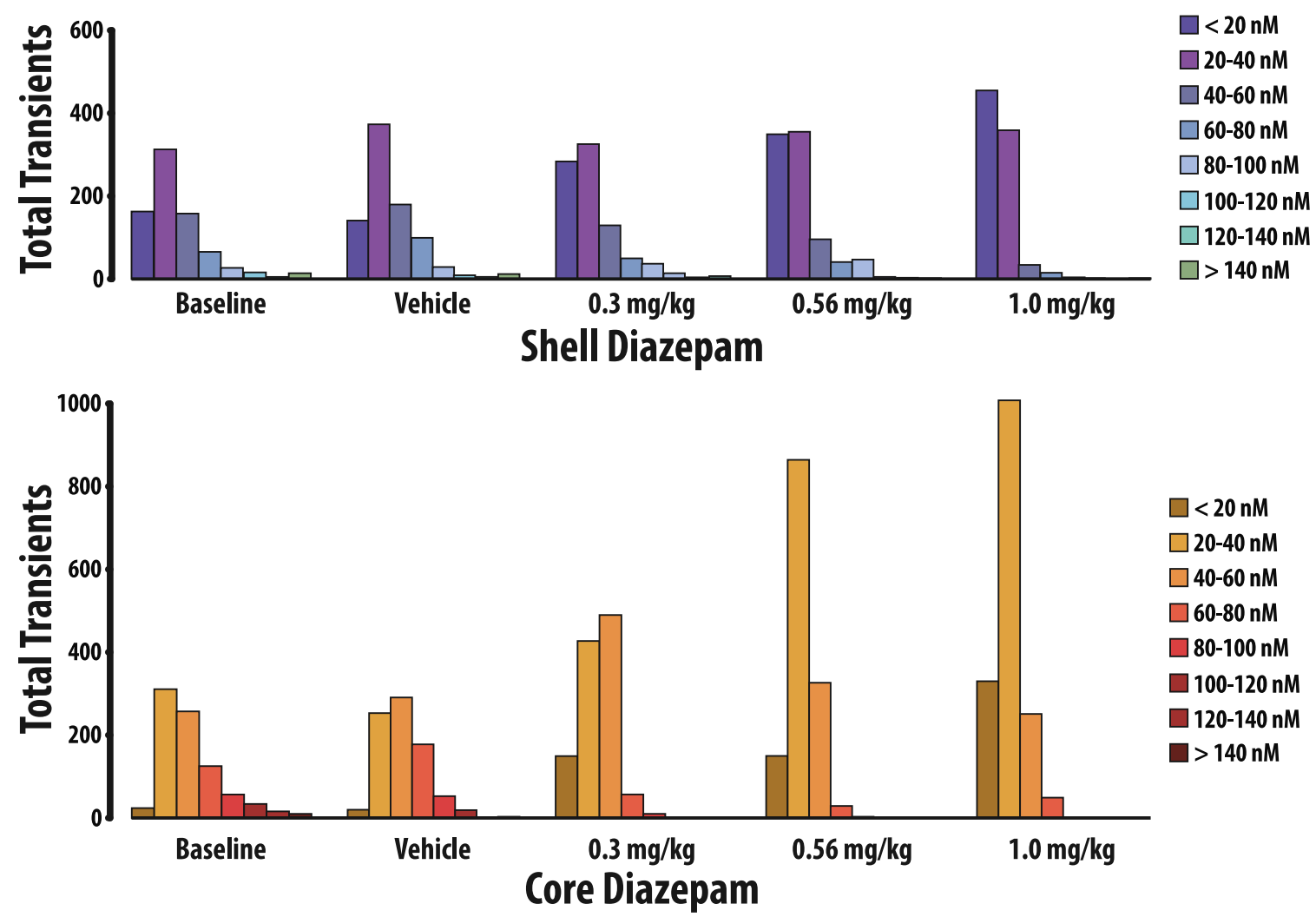

Fig. 6. Histograms showing total transients in the shell (top) and core (bottom) across baseline, vehicle, and all diazepam conditions. These figures illustrate both a diazepam-induced loss of higher-amplitude DA events and an increase in lower amplitude DA events.

The paradoxical electrophysiological and microdialysis findings might suggest that BZPs disinhibit DA neurons, but also decrease the concentration of DA released into the NAc through independent mechanisms. It is possible that the electrophysiological results represent a disinhibition of DA neural activity in the VTA (O'Brien and White, 1987; Tan et al., 2010), which increases both the frequency and amplitude of accumbal transient release events. By contrast, the microdialysis results (Zetterström and Fillenz, 1990; Invernizzi et al., 1991; Finlay et al., 1992, 1995; Takada et al., 1993; Murai et al., 1994; Dazzi et al., 1995; Hegarty and Vogel, 1995; Motzo et al., 1997; Yoshida et al., 1999; Bentue-Ferrer et al., 2001; Rada and Hoebel, 2005; Gomez-A et al., 2017) and the recent anesthetized FSCV study (Gomez-A et al., 2017) might represent a localized suppression of accumbal DA release events. However, it should also be noted that the aforementioned electrophysiological studies identified dopamine neurons solely using electrophysiological criteria-which is now considered insufficient to determine whether a recorded unit is DAergic or GABAergic (Ungless et al., 2004; Ungless and Grace, 2012).

In the current study, we predicted that a real-time analysis of BZP-induced accumbal DA release events would reveal an increase in their frequency, but also a decrease in their amplitude. To address this hypothesis, we performed FSCV in the awake and freely moving rat and observed that the BZP diazepam increased the frequency of DA release events while also decreasing their amplitude. The time course over which BZPs altered the frequency and amplitude of DA release events diverged, with the decreased amplitude effect being shorter lived than the increase in frequency, but both showing similar rates of onset. The divergent time course may suggest that these two effects are governed by distinct neural mechanisms. We observed similar effects in both the core and shell regions of the NAc, and they were reversed by treatment with the selective BZP-site antagonist flumazenil.

Emerging evidence suggests that a unifying action of all abused substances is their ability to increase DA transient release events (Covey et al., 2014). Although many mechanisms of action have been identified through which abused substances increase brain DA concentrations, a unifying feature is that all drugs of abuse increase high-concentration transient release events (Covey et al., 2014). To date, most drugs of abuse, including cocaine, amphetamine, opiates, cannabis, and nicotine, have been shown to increase both the frequency and amplitude of transient release events (Covey et al., 2014). However, in the current study, we found that BZPs increase the frequency, but decrease the amplitude of transient release events. Similar results have been reported with ethanol (Cheer et al., 2007; Robinson et al., 2009), which is similar to BZPs in that it is known to activate GABA receptors (Valenzuela and Jotty, 2015; Ostroumov et al., 2016). It is possible that NAc-localized GABA modulation of VTA dopaminergic terminals may contribute to reductions in amplitude of DA release.

BZPs are known to produce moderate abuse liability (Griffiths and Weerts, 1997; Licata and Rowlett, 2008; Baldwin et al., 2013) and potentiate brain reward function (Straub et al., 2010), but also alter the rewarding and reinforcing properties of other abused drugs. Sedativehypnotics, including BZPs, are frequently coabused with psychostimulants to self-medicate insomnia, agitation, and irritability (Wesson and Smith, 1985). Similarly, sedative- 


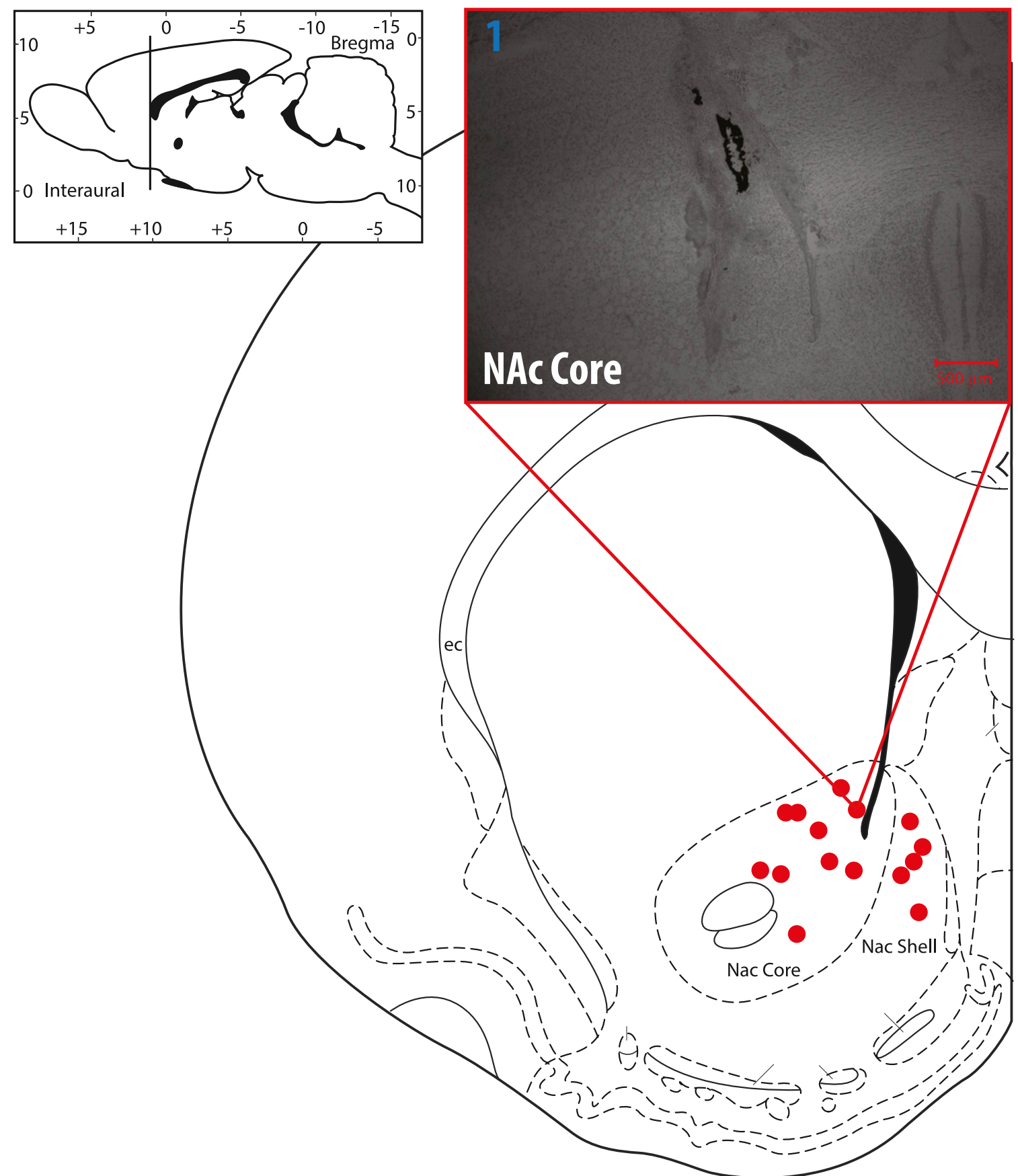

Fig. 7. Electrolytic lesions confirm electrode placement within the NAc core and shell. Representative image (upper right) of NAc core lesion.

hypnotics can be used to treat anxiety and psychosis in cocaine abusers (Wesson and Smith, 1985). Cocaine was first shown to produce anxiogenic-like stimulus effects in the preclinical literature by Wood and Lal (1987). Using drug discrimination, these authors demonstrated that the anxiogenic drug pentylenetetrazol generalizes to cocaine withdrawal (Wood and Lal, 1987), an effect that was blocked by diazepam (Wood et al., 1989). The benzodiazepine alprazolam was also shown to reduce the discriminative stimulus effects of amphetamine (Rush et al., 2004). A variety of benzodiazepines have also been shown to reduce distress ultrasonic vocalization in rodents (Rowlett et al., 2001; Hodgson et al., 2008). Goeders et al. (1993) and Goeders (1997, 2002) expanded upon these findings by demonstrating that benzodiazepines concurrently reduce stress-associated adrenocorticosteroids and cocaine self-administration. More recently, their group demonstrated that a combination of the BZPs metyrapone and oxazepam reduces cocaine self-administration under an FR4 schedule in rats (Goeders and Guerin, 2008) and cocaine craving and cocaine taking in a double-blind, randomized, placebo-controlled pilot study (Kablinger et al., 2012). Benzodiazepines are also commonly used to treat symptoms of withdrawal during detoxification from alcohol (Kosten and O'Connor, 2003; Zindel and Kranzler, 2014). Given the well established yet complex interactions between the hypothalamic-pituitary-adrenal axis and the mesocorticolimbic 
system (Ungless et al., 2003; Beckstead et al., 2009), it is likely that benzodiazepines alter the abuse potential of other drugs through both direct and indirect actions on both systems. Further studies are needed to determine how BZP-induced changes in DA release are altered during polydrug administration and in animal models of drug addiction.

\section{Acknowledgments}

We thank Dr. Dan P. Covey and Dr. Joseph F. Cheer for helpful comments in the preparation of this manuscript.

\section{Authorship Contributions}

Participated in research design: Brodnik, España, Oleson.

Conducted experiments: Schelp, Rakowski, Pultorak, Sambells.

Performed data analysis: Schelp, Oleson.

Wrote or contributed to the writing of the manuscript: Schelp, Oleson.

\section{References}

Aragona BJ, Cleaveland NA, Stuber GD, Day JJ, Carelli RM, and Wightman RM (2008) Preferential enhancement of dopamine transmission within the nucleus accumbens shell by cocaine is attributable to a direct increase in phasic dopamine release events. $J$ Neurosci 28:8821-8831.

Baldwin DS, Aitchison K, Bateson A, Curran HV, Davies S, Leonard B, Nutt DJ, Stephens DN, and Wilson S (2013) Benzodiazepines: risks and benefits. A reconsideration. J Psychopharmacol 27:967-971.

Beckstead MJ, Gantz SC, Ford CP, Stenzel-Poore MP, Phillips PE, Mark GP, and Williams JT (2009) CRF enhancement of GIRK channel-mediated transmission in dopamine neurons. Neuropsychopharmacology 34:1926-1935.

Bentué-Ferrer D, Reymann JM, Tribut O, Allain H, Vasar E, and Bourin M (2001) Role of dopaminergic and serotonergic systems on behavioral stimulatory effects of low-dose alprazolam and lorazepam. Eur Neuropsychopharmacol 11:41-50.

Braestrup C and Squires RF (1977) Specific benzodiazepine receptors in rat brain characterized by high-affinity (3H)diazepam binding. Proc Natl Acad Sci USA 74 3805-3809.

Centers for Disease Control and Prevention (CDC) (2010) Emergency department visits involving nonmedical use of selected prescription drugs - United States, 2004-2008. MMWR Morb Mortal Wkly Rep 59:705-709.

Cheer JF, Wassum KM, Heien ML, Phillips PE, and Wightman RM (2004) Cannabinoids enhance subsecond dopamine release in the nucleus accumbens of awake rats. J Neurosci 24:4393-4400.

Cheer JF, Wassum KM, Sombers LA, Heien ML, Ariansen JL, Aragona BJ, Phillips $\mathrm{PE}$, and Wightman RM (2007) Phasic dopamine release evoked by abused substances requires cannabinoid receptor activation. $J$ Neurosci 27:791-795.

Covey DP, Bunner KD, Schuweiler DR, Cheer JF, and Garris PA (2016) Amphetamine elevates nucleus accumbens dopamine via an action potential-dependent mechanism that is modulated by endocannabinoids. Eur $J$ Neurosci 43:1661-1673.

Covey DP, Roitman MF, and Garris PA (2014) Illicit dopamine transients: reconciling actions of abused drugs. Trends Neurosci 37:200-210.

Da Cunha C, Gomez-A A, and Blaha CD (2012) The role of the basal ganglia in motivated behavior. Rev Neurosci. 23:747-767.

Dazzi L, Motzo C, Imperato A, Serra M, Gessa GL, and Biggio G (1995) Modulation of basal and stress-induced release of acetylcholine and dopamine in rat brain by abecarnil and imidazenil, two anxioselective gamma-aminobutyric acidA receptor modulators. J Pharmacol Exp Ther 273:241-247.

Dell'osso B and Lader M (2013) Do benzodiazepines still deserve a major role in the treatment of psychiatric disorders? A critical reappraisal. Eur Psychiatry 28:7-20.

Di Chiara G and Imperato A (1988) Drugs abused by humans preferentially increase synaptic dopamine concentrations in the mesolimbic system of freely moving rats. Proc Natl Acad Sci USA 85:5274-5278.

Finlay JM, Damsma G, and Fibiger HC (1992) Benzodiazepine-induced decreases in extracellular concentrations of dopamine in the nucleus accumbens after acute and repeated administration. Psychopharmacology (Berl) 106:202-208.

Finlay JM, Zigmond MJ, and Abercrombie ED (1995) Increased dopamine and norepinephrine release in medial prefrontal cortex induced by acute and chronic stress: effects of diazepam. Neuroscience 64:619-628.

Floresco SB (2015) The nucleus accumbens: an interface between cognition, emotion, and action. Annu Rev Psychol 66:25-52.

Fox ME, Rodeberg NT, and Wightman RM (2017) Reciprocal catecholamine changes during opiate exposure and withdrawal. Neuropsychopharmacology. 42: 671-681.

Goeders NE (1997) A neuroendocrine role in cocaine reinforcement. Psychoneuroendocrinology 22:237-259.

Goeders NE (2002) The HPA axis and cocaine reinforcement. Psychoneuroendocrinology 27:13-33.

Goeders NE and Guerin GF (2008) Effects of the combination of metyrapone and oxazepam on cocaine and food self-administration in rats. Pharmacol Biochem Behav 91:181-189.

Goeders NE, McNulty MA, and Guerin GF (1993) Effects of alprazolam on intravenous cocaine self-administration in rats. Pharmacol Biochem Behav 44 471-474

Gomez-A A, Fiorenza AM, Boschen SL, Sugi AH, Beckman D, Ferreira ST, Lee K Blaha CD, and Da Cunha C (2017) Diazepam inhibits electrically evoked and tonic dopamine release in the nucleus accumbens and reverses the effect of amphetamine. ACS Chem Neurosci 8:300-309.

Grace AA and Bunney BS (1984) The control of firing pattern in nigral dopamine neurons: burst firing. $J$ Neurosci 4:2877-2890.

Grace AA, Floresco SB, Goto Y, and Lodge DJ (2007) Regulation of firing of dopaminergic neurons and control of goal-directed behaviors. Trends Neurosci 30: $220-227$.

Griffiths RR and Weerts EM (1997) Benzodiazepine self-administration in humans and laboratory animals-implications for problems of long-term use and abuse. Psychopharmacology (Berl) 134:1-37.

Hegarty AA and Vogel WH (1995) The effect of acute and chronic diazepam treatment on stress-induced changes in cortical dopamine in the rat. Pharmacol Biochem Behav 52:771-778.

Heien ML, Johnson MA, and Wightman RM (2004) Resolving neurotransmitters detected by fast-scan cyclic voltammetry. Anal Chem 76:5697-5704.

Heien ML, Phillips PE, Stuber GD, Seipel AT, and Wightman RM (2003) Overoxidation of carbon-fiber microelectrodes enhances dopamine adsorption and increases sensitivity. Analyst (Lond) 128:1413-1419.

Hodgson RA, Guthrie DH, and Varty GB (2008) Duration of ultrasonic vocalizations in the isolated rat pup as a behavioral measure: sensitivity to anxiolytic and an tidepressant drugs. Pharmacol Biochem Behav 88:341-348.

Ikemoto S (2007) Dopamine reward circuitry: two projection systems from the ventral midbrain to the nucleus accumbens-olfactory tubercle complex. Brain Res Brain Res Rev 56:27-78.

Invernizzi R, Pozzi L, and Samanin R (1991) Release of dopamine is reduced by diazepam more in the nucleus accumbens than in the caudate nucleus of conscious rats. Neuropharmacology 30:575-578.

Kablinger AS, Lindner MA, Casso S, Hefti F, DeMuth G, Fox BS, McNair LA, McCarthy BG, and Goeders NE (2012) Effects of the combination of metyrapone and oxazepam on cocaine craving and cocaine taking: a double-blind, randomized, placebo-controlled pilot study. J Psychopharmacol 26:973-981.

Kosten TR and O'Connor PG (2003) Management of drug and alcohol withdrawal. $N$ Engl J Med 348:1786-1795.

Licata SC and Rowlett JK (2008) Abuse and dependence liability of benzodiazepinetype drugs: GABA(A) receptor modulation and beyond. Pharmacol Biochem Behav 90:74-89.

Motzo C, Porceddu ML, Dazzi L, Sanna A, Serra M, and Biggio G (1997) Enhancement by flumazenil of dopamine release in the nucleus accumbens of rats repeatedly exposed to diazepam or imidazenil. Psychopharmacology (Berl) 131 $34-39$

Murai T, Koshikawa N, Kanayama T, Takada K, Tomiyama K, and Kobayashi M (1994) Opposite effects of midazolam and $\beta$-carboline-3-carboxylate ethyl ester on the release of dopamine from rat nucleus accumbens measured by in vivo microdialysis. Eur J Pharmacol 261:65-71.

O'Brien DP and White FJ (1987) Inhibition of non-dopamine cells in the ventral tegmental area by benzodiazepines: relationship to A10 dopamine cell activity. Eur $J$ Pharmacol 142:343-354.

Oleson EB and Cheer JF (2012) A brain on cannabinoids: the role of dopamine release in reward seeking. Cold Spring Harb Perspect Med 2:a012229.

Ostroumov A, Thomas AM, Kimmey BA, Karsch JS, Doyon WM, and Dani JA (2016) Stress increases ethanol self-administration via a shift toward excitatory GABA signaling in the ventral tegmental area. Neuron 92:493-504.

Rada P and Hoebel BG (2005) Acetylcholine in the accumbens is decreased by diazepam and increased by benzodiazepine withdrawal: a possible mechanism for dependency. Eur $J$ Pharmacol 508:131-138.

Roberts JG, Toups JV, Eyualem E, McCarty GS, and Sombers LA (2013) In situ electrode calibration strategy for voltammetric measurements in vivo. Anal Chem 85:11568-11575.

Robinson DL, Howard EC, McConnell S, Gonzales RA, and Wightman RM (2009) Disparity between tonic and phasic ethanol-induced dopamine increases in the nucleus accumbens of rats. Alcohol Clin Exp Res 33:1187-1196.

Rowlett JK, Tornatzky W, Cook JM, Ma C, and Miczek KA (2001) Zolpidem, triazolam, and diazepam decrease distress vocalizations in mouse pups: differential antagonism by flumazenil and $\beta$-Carboline-3-carboxylate-t-butyl ester $(\beta$-CCt). $J$ Pharmacol Exp Ther 297:247-253.

Rudolph U and Möhler H (2006) GABA-based therapeutic approaches: GABAA receptor subtype functions. Curr Opin Pharmacol 6:18-23.

Rush CR, Stoops WW, Wagner FP, Hays LR, and Glaser PE (2004) Alprazolam attenuates the behavioral effects of d-amphetamine in humans. J Clin Psychopharmacol 24:410-420.

Sigel E and Buhr A (1997) The benzodiazepine binding site of GABAA receptors Trends Pharmacol Sci 18:425-429.

Straub CJ, Carlezon WA, Jr, and Rudolph U (2010) Diazepam and cocaine potentiate brain stimulation reward in C57BL/6J mice. Behav Brain Res 206:17-20.

Stuber GD, Roitman MF, Phillips PE, Carelli RM, and Wightman RM (2005) Rapid dopamine signaling in the nucleus accumbens during contingent and noncontingent cocaine administration. Neuropsychopharmacology 30:853-863.

Swanson LW (1982) The projections of the ventral tegmental area and adjacent regions: a combined fluorescent retrograde tracer and immunofluorescence study in the rat. Brain Res Bull 9:321-353.

Takada K, Murai T, Kanayama T, and Koshikawa N (1993) Effects of midazolam and flunitrazepam on the release of dopamine from rat striatum measured by in vivo microdialysis. $\mathrm{Br}$ J Anaesth 70:181-185.

Tan KR, Brown M, Labouèbe G, Yvon C, Creton C, Fritschy J-M, Rudolph U, and Lüscher C (2010) Neural bases for addictive properties of benzodiazepines. Nature 463:769-774.

Tan KR, Rudolph U, and Lüscher C (2011) Hooked on benzodiazepines: GABAA receptor subtypes and addiction. Trends Neurosci 34:188-197.

Umbricht A and Velez ML (2015) Benzodiazepine abuse and addiction, in Textbook of Addiction Treatment: International Perspectives. pp 343-365. Springer, Milan. 
Ungless MA and Grace AA (2012) Are you or aren't you? Challenges associated with physiologically identifying dopamine neurons. Trends Neurosci $\mathbf{3 5}$ 422-430.

Ungless MA, Magill PJ, and Bolam JP (2004) Uniform inhibition of dopamine neurons in the ventral tegmental area by aversive stimuli. Science 303:2040-2042.

Ungless MA, Singh V, Crowder TL, Yaka R, Ron D, and Bonci A (2003) Corticotropinreleasing factor requires $\mathrm{CRF}$ binding protein to potentiate NMDA receptors via CRF receptor 2 in dopamine neurons. Neuron 39:401-407.

Valenzuela CF and Jotty K (2015) Mini-review: effects of ethanol on GABAA receptor-mediated neurotransmission in the cerebellar cortex-recent advances. Cerebellum 14:438-446.

Wesson DR and Smith DE (1985) Cocaine: treatment perspectives, in Cocaine use in America. Epidemiologic and Clinical Perspectives National Institute on Drug Abuse Research Monograph Series 61, pp 193-202, National Institute on Drug Abuse, Rockville, MD.

Willuhn I, Wanat MJ, Clark JJ, and Phillips PE (2010) Dopamine signaling in the nucleus accumbens of animals self-administering drugs of abuse, in Behavioral Neuroscience of Drug Addiction (Self DW and Staley JK eds), pp 29-71, SpringerVerlag, Berlin, Heidelberg.
Wood DM and Lal H (1987) Anxiogenic properties of cocaine withdrawal. Life Sciences 41:1431-36.

Wood DM, Laraby PR, and Lal H (1989) A pentylenetetrazol-like stimulus during cocaine withdrawal: blockade by diazepam but not haloperidol. Drug Dev Res 16: $269-276$

Yoshida Y, Koide S, Hirose N, Takada K, Saigusa T, and Koshikawa N (1999) In vivo microdialysis evidence that midazolam facilitates propofol-induced reduction in rat accumbal dopamine release. Neurosci Res Commun 25:121-127.

Zetterström T and Fillenz M (1990) Local administration of flurazepam has different effects on dopamine release in striatum and nucleus accumbens: a microdialysis study. Neuropharmacology 29:129-134.

Zindel LR and Kranzler HR (2014) Pharmacotherapy of alcohol use disorders: seventy-five years of progress. J Stud Alcohol Drugs Suppl 75 (Suppl 17):79-88.

Address correspondence to: Erik B. Oleson, CB 173, P.O. Box 173364, University of Colorado Denver, Denver, CO 80217. E-mail: erik.oleson@ ucdenver.edu 